\title{
Sero-epidemiological study of Lyme disease among high-risk population groups in eastern Slovakia
}

\author{
Lubica Zákutná', Erik Dorko', Eva Mattová2, Kvetoslava Rimárová1 \\ ${ }^{1}$ Department of Public Health and Hygiene, Faculty of Medicine, University of P. J. Šafárik, Košice, Slovakia \\ ${ }^{2}$ Clinic of Infectology and Travel Medicine, L. Pasteur University Hospital, Košice, Slovakia
}

Zákutná L, Dorko E, Mattová E, Rimárová K. Sero-epidemiological study of Lyme disease among high-risk population groups in eastern Slovakia. Ann Agric Environ Med. 2015; 22(4): 632-636. doi: 10.5604/12321966.1185765

\begin{abstract}
Introduction and objective. The aim of the presented cross-sectional sero-epidemiological study was to determine the current presence of antibodies against B. burgdorferi s.l. in the high-risk groups of the Slovak population, and to identify potential risk factors to LB infections.

Materials and method. A group of 277 agricultural and forestry workers - persons with frequent stay in the countryside and employees of State Border and Customs Police - from years 2011-2012 in the Eastern Slovakia were examined in order to assess the seroprevalence of anti-Borrelia antibodies. Sera were screened by commercial enzyme-linked immunosorbent assay (ELISA). The study subjects completed a questionnaires with general demographic, epidemiological and clinical data. The results were evaluated statistically.

Results. A $25.3 \%$ presence of positive and $8.7 \%$ presence of borderline IgG antibodies was detected in all investigated groups. The seroprevalence of $B$. burgdorferi s.l. was significantly higher $(\mathrm{P}<0.05)$ among the agricultural and forestry workers when compared to employees of State Border and Customs Police. Higher seropositivity was observed in older subjects over 30 years of age $(P=0.004)$ than those who were younger, and also in males $(P=0.045)$. A significant number of persons with rheumatologic conditions was statistically higher $(P=0.020)$ in the group with seropositivity than in the group with seronegativity.

Conclusions. The presented study confirms the higher risk of Borrelia infection in individuals with frequent exposure to ticks in eastern Slovakia. The seropositivity tests confirmed the highest seropositivity in agriculture and forestry workers, middle positivity was confirmed among other sector workers, and lowest positivity in policemen and employees of the Customs and Border Inspection. The outputs also simultaneously filling the gap of missing seroprevalence data among these exposed groups.
\end{abstract}

- Key words

Lyme disease, Borrelia, seroprevalence, ELISA, exposed groups, Slovakia

\section{INTRODUCTION}

Lyme borreliosis (LB) is the most prevalent tick-borne zoonosis in the northern hemisphere. It is caused by spirochetes belonging to Borrelia burgdorferi (B.b.) sensu lato (s.l.) complex which are transmitted by ticks, in Europe by Ixodes (I.) ricinus $[1,2]$. B. afzelii and B. garinii are the most common European circulating genospecies [3, 4].

The highest incidence of LB in Europe was noticed in the Baltic countries, Sweden, Austria, Czech Republic, Germany, Slovenia, and in other countries of central Europe [4]. From the epidemiological reports of the Specialized State Health Institute in Banská Bystrica it appears that the number of patients with LB in Slovakia has increased from 59 cases recorded in 1986 [5] to 1,054 (incidence 19.43/100.000) cases in 2010. In 2011, 852 cases were reported (incidence $15.68 / 100.000$ ); while in 2012, the number dropped to 754 cases (incidence 13.95/100.000) [6].

The main clinical manifestations of LB include: early localized disease (erythema migrans), early disseminated disease (neuroborreliosis, arthritis, carditis) and late disease

Address for correspondence: Erik Dorko, Department of Public Health and Hygiene, Faculty of Medicine, University of P. J. Šafárik, Košice, Slovakia

E-mail: erik.dorko@upjs.sk

Received: 04 March 2014; accepted: 14 April 2015 (acrodermatitis chronica atrophicans, Lyme arthritis and late neuroborreliosis) $[1,4]$.

The routine diagnosis of borreliosis in humans is based on detection of the specific antibodies levels - IgM and IgG classes, mainly in blood, cerebrospinal fluid, and synovial fluid. According to guidelines promulgated in the USA and Germany, serological diagnosis should follow the principles of a two-step procedure, with an enzyme-linked immunosorbent assay (ELISA) as the first step; if reactive, this step is followed by immunobloting $[7,8]$. Specific antibodies from the IgM class are formed 2-4 weeks after the onset of primary infection [9]. IgG antibodies appear in serum 6 weeks after infection, they reach their peak level after 4-6 months and are detectable in serum for more than next 10 years $[1,7,10]$.

Since forests and woods are the preferred ecosystems of ticks, the risk of contracting LB is higher among forestry workers, farmers and other workers in wooded areas, as well as hunters, tourists, and forest undergrowth pickers staying in areas of the highest tick activities $[3,11]$.

The aim of this study was to investigate the current seroprevalence of LB in the risk groups of population in eastern Slovakia, e.g.: agriculture workers, forestry workers and police forces, and to determine associations of seroprevalence with selected risk factors. 


\section{MATERIALS AND METHODS}

Venous blood samples were taken from persons $(n=227)$ exposed to tick bite, working on the land, in agriculture, forestry employees of State Border and Customs Police, and persons frequently staying in the countryside risk areas of Eastern Slovakia - (hereafter referred as the 'other sector') in years of 2011-2012. The study subjects filled out a questionnaire and signed a written informed consent about blood collection and a consent to the processing of data for scientific purpose.

The serum was obtained by centrifugation $(2,500 \mathrm{rpm} /$ $10 \mathrm{~min}$.) and preserved at $-80^{\circ} \mathrm{C}$ until serological testing.

ELISA anti-Borrelia plus VlsE (Euroimmun, Germany) was used in order to examine the IgG antibodies in serum samples from the individuals. This test contained recombinant $B$. burgdorferi VlsE (variable major proteinlike sequence expressed) antigen and whole cell lysate antigen from B. burgdorferi sensu stricto, B. afzelii, and $B$. garinii. The test procedure was performed according to the manufacturer's instructions, and optical density was measured with a spectrophotometer at $450 \mathrm{~nm}$ using an ELISA reader (Synergy HT BioTek). Evaluation of the sample results detected was semi-quantitative as negative, borderline and positive.

The questionnaire submitted to all respondents contained: 1) demographic data: gender; age; residence; occupation;

2) epidemiological data: tick bite; use of repellents; agricultural field and/or forest exposure; activities, such as gardening and hunting; contact with animals at work; pet ownership; drinking unpasteurised milk and/or consuming products from this milk.

3) clinical personal history: history of symptoms that could be associated with LB - dermatological (severe redness after tick bite, red spots, ulcers), rheumatologic (above all, pains in joints, muscle pain, stiff neck), neurological complaints (paralysis of the facial nerve or other nerves, headache, pain behind the eyes, tinnitus, insomnia, night sweats, weakness, muscle twitching, etc.), and presence of chronic fatigue syndrome.

Statistical methods. Study results were presented as odds ratio (OR) with $95 \%$ confidence interval (CI). The statistical significance level was considered $\mathrm{P}<0.05$. For calculations of potential risk factors for seropositivity, Epi-Info version 7 software was used. Sera with the borderline (equivocal) values of antibodies represent a separate group with uncertain result and were thus excluded from analysis.

\section{RESULTS}

Characteristics of the investigated group. The crosssectional study included $69.7 \%$ of people with direct or particular occupational exposure to tick bite in the areas of forestry and agriculture: mostly employees of agricultural farms and forests (veterinary technicians, shepherds, drivers, agricultural machinery maintenance staff, workers on farms, workers in vineyards, foresters); $17.3 \%$ working in other sectors but with frequent staying in the countryside; and $13 \%$ members of State Border and Customs Police with partial exposition during their job activities in grasslands and forests.
In terms of gender, $200(72.2 \%)$ males and 77 (27.8\%) females were examined. The sample was created predominantly by people in the productive age between $30-50$ years (44.4\%) and over 50 years $(36.8 \%)$, while the group with the age of up to 30 years was the smallest (18.8\%). Urban residents comprised $24.5 \%(n=68)$ of the sample, $75.5 \%(n=209)$ of the subjects resided in rural areas.

A history of a tick bite was reported in $87 \%(n=241)$ of cases. Repellents commonly used were recorded by $49 \%$ $(n=99)$ of positive respondents. Respondents reported the following outdoor activities: $76.9 \%(n=213)$ of respondents often stayed or worked in agricultural fields and/or woods, $76.9 \%(n=213)$ worked in gardens, and $37.2 \%(n=103)$ were involved in hunting activities. The majority of respondents (77.6\%) had some contact with the animals during work, and $64.4 \%$ contact with their own pets.

Dermatological complaints were observed in $13 \%(n=36)$ of respondents, rheumatologic complaints in $35.7 \%(n=99)$ and $16.2 \%(n=45)$ reported neurological disorders. Chronic fatigue syndrome was present in $10.5 \%$ of subjects (Tab. 1).

Presence of IgG antibodies against B. burgdorferi. Positive values of IgG antibodies were detected in $25.3 \%(\mathrm{n}=70)$, borderline values in $8.7 \%(n=24)$ and negative results in $66 \%(n=183)$ of cases among the investigated group (Tab. 2$)$.

Table 1. Demographic and exposure characteristics of the investigated group

\begin{tabular}{|c|c|c|c|}
\hline \multirow{2}{*}{\multicolumn{2}{|c|}{ Risk factors / characteristics }} & \multicolumn{2}{|c|}{ Subjects } \\
\hline & & \multirow{2}{*}{$\frac{n}{68}$} & \multirow{2}{*}{$\begin{array}{c}\% \\
24.5\end{array}$} \\
\hline & urban & & \\
\hline Residence & rural & 209 & 75.5 \\
\hline \multirow{3}{*}{ Occupation } & agricultural and forestry workers & 193 & 69.7 \\
\hline & State Border and Customs Police & 36 & 13.0 \\
\hline & other sector & 48 & 17.3 \\
\hline \multirow{2}{*}{ Gender } & male & 200 & 72.2 \\
\hline & female & 77 & 27.8 \\
\hline \multirow{2}{*}{ Age } & younger (up to 30 years) & 52 & 18.8 \\
\hline & middle and older (over 30 years) & 225 & 81.2 \\
\hline \multirow{2}{*}{ Tick bite } & + & 241 & 87.0 \\
\hline & - & 36 & 13.0 \\
\hline \multirow{2}{*}{ Using repellents } & + & 99 & 49.0 \\
\hline & - & 103 & 51.0 \\
\hline \multirow{2}{*}{$\begin{array}{l}\text { Agricultural field and/or } \\
\text { forest exposure }\end{array}$} & + & 213 & 76.9 \\
\hline & - & 64 & 23.1 \\
\hline \multirow{2}{*}{ Gardening } & + & 213 & 76.9 \\
\hline & - & 64 & 23.1 \\
\hline \multirow{2}{*}{ Hunting } & + & 103 & 37.2 \\
\hline & - & 174 & 62.8 \\
\hline \multirow{2}{*}{$\begin{array}{l}\text { Contact with animals } \\
\text { in work }\end{array}$} & + & 215 & 77.6 \\
\hline & - & 62 & 22.4 \\
\hline \multirow{2}{*}{ Contact with pets } & + & 116 & 64.4 \\
\hline & - & 64 & 35.6 \\
\hline \multirow{2}{*}{$\begin{array}{l}\text { Dermatological } \\
\text { complaints }\end{array}$} & + & 36 & 13.0 \\
\hline & - & 241 & 87.0 \\
\hline \multirow{2}{*}{$\begin{array}{l}\text { Rheumatologic } \\
\text { complaints }\end{array}$} & + & 99 & 35.7 \\
\hline & - & 178 & 64.3 \\
\hline \multirow{2}{*}{$\begin{array}{l}\text { Neurological } \\
\text { complaints }\end{array}$} & + & 45 & 16.2 \\
\hline & - & 232 & 83.8 \\
\hline \multirow{2}{*}{$\begin{array}{l}\text { Chronic fatigue } \\
\text { syndrome }\end{array}$} & + & 29 & 10.5 \\
\hline & - & 248 & 89.5 \\
\hline
\end{tabular}


Table 2. The results of serology of lgG antibodies against $B$. burgdorferi s.I. by ELISA among all of the examined individuals

\begin{tabular}{lcc}
\hline IgG ELISA & $\mathrm{n}$ & $\%$ \\
\hline Positive & 70 & 25.3 \\
\hline Negative & 183 & 66.0 \\
\hline Borderline & 24 & 8.7 \\
\hline Total & 277 & 100 \\
\hline
\end{tabular}

Presence of IgG antibodies against B. burgdorferi in groups by occupational sector. The most positive samples from all investigated persons were the agricultural and forestry workers (29\%), followed by employees in the other sector (21\%), while the group of policemen showed the lowest incidence - $11 \%$ (Tab. 3).

Table 3. The results of serology of IgG antibodies against $B$. burgdorferi s.I. by ELISA among different exposure sectors

\begin{tabular}{lcccc}
\hline IgG ELISA & Positive & Negative & Borderline & Total \\
& $\mathrm{n}$ & $\mathrm{n}$ & $\mathrm{n}$ & $\mathrm{n}$ \\
& $(\%)$ & $(\%)$ & $(\%)$ & $(\%)$ \\
\hline Agriculture and forestry workers & 56 & 122 & 15 & 193 \\
& $(29.2)$ & $(63.2)$ & $(7.8)$ & $(100)$ \\
\hline Police and border custom & 4 & 28 & 4 & 36 \\
\hline Others & $(11.1)$ & $(77.8)$ & $(11.1)$ & $(100)$ \\
\hline Total & 10 & 33 & 5 & 48 \\
\hline & $(20.8)$ & $(68.8)$ & $(10.4)$ & $(100)$ \\
\hline
\end{tabular}

Association of IgG with residence, gender, age. A slightly higher seroprevalence was observed in subjects with a rural life $(\mathrm{OR}=1.741 ; \mathrm{CI}=0.879-3.444 ; \mathrm{P}=0.109)$, compared to the urban residents. The respondents older than 30 years had significantly ( 3.7 times) higher probability to be seropositive $(\mathrm{P}=0.004)$ than younger subjects. The ORs of being seropositive was 1.9 times significantly higher for males $(\mathrm{OR}=1.983 ; \mathrm{CI}=1.006-3.910 ; \mathrm{P}=0.045)$ compared to females (Tab. 4).

Association of IgG with occupation. Statistically, a higher probability for seropositivity was observed among agriculture and forestry workers when compared to the employees of the police forces $(\mathrm{OR}=3.213 ; \mathrm{CI}=1.075-9.598 ; \mathrm{P}=0.029)$ and to the persons in the other sector, although with an insignificant level for the latter $(\mathrm{OR}=1.514 ; \mathrm{CI}=0.697-3.288$; $\mathrm{P}=0.292)$ (Tab. 4).

Association of IgG with tick bite, using repellents. Contact with tick bite was reported in $87 \%$ of respondents, but this factor was not statistically significant $(\mathrm{OR}=1.122$; $\mathrm{CI}=0497-2.532 ; \mathrm{P}=0.781$ ) for seropositivity. On the other hand, individuals who used repellents had lower odds to be seropositive $(\mathrm{OR}=0.542 ; \mathrm{CI}=0.279-1.056 ; \mathrm{P}=0.070)(\mathrm{Tab} .4)$.

Association of IgG with outdoor activities. The seropositivity rate was 1.9 times higher in persons working, or frequently staying in the woods or agricultural fields, with a close level the significance $(\mathrm{P}=0.077)$. Persons working in gardens were 1.7 times more likely to have the presence of antibodies than the others, and it was insignificant $(\mathrm{OR}=1.718$; $\mathrm{CI}=0.850$ $3.472 ; \mathrm{P}=0.129)$. The $\mathrm{OR}$ for seroreactivity in the hunting and
Table 4. OR of potential risk factors for the presence IgG antibodies in study group

\begin{tabular}{|c|c|c|c|}
\hline Factor & OR & $\mathrm{Cl} 95 \%$ & $\mathrm{p}$-value \\
\hline Residence: rural/urban & 1.741 & $0.879-3.444$ & 0.109 \\
\hline $\begin{array}{l}\text { Occupation: agricultural and forestry workers/ } \\
\text { police and } \\
\text { other sector }\end{array}$ & 2.000 & $1.032-3.875$ & $0.040^{*}$ \\
\hline $\begin{array}{l}\text { Occupation: agricultural and forestry workers / } \\
\text { police }\end{array}$ & 3.213 & $1.075-9.598$ & $0.037^{*}$ \\
\hline $\begin{array}{l}\text { Occupation: agricultural and forestry workers / } \\
\text { other sector }\end{array}$ & 1.515 & $0.697-3.288$ & 0.294 \\
\hline Gender: male / female & 1.983 & $1.006-3.910$ & $0.045^{*}$ \\
\hline Age: older / younger & 3.753 & $1.417-9.938$ & $0.004^{* *}$ \\
\hline Tick bite + / - & 1.122 & $0.497-2.532$ & 0.781 \\
\hline Using repellents + / - & 0.542 & $0.279-1.056$ & 0.070 \\
\hline Agricultural field and/or forest exposure + / - & 1.907 & $0.920-3.930$ & 0.077 \\
\hline Gardening + / - & 1.718 & $0.850-3.472$ & 0.129 \\
\hline Hunting $+/-$ & 0.976 & $0.552-1.725$ & 0.934 \\
\hline $\begin{array}{l}\text { Contact with animals } \\
\text { at work }+/-\end{array}$ & 1.266 & $0.631-2.537$ & 0.506 \\
\hline Contact with pets $+/-$ & 0.949 & $0.457-1.970$ & 0.961 \\
\hline Dermatological complaints +/ - & 0.309 & $0.104-0.912$ & $0.026^{*}$ \\
\hline Rheumatologic complaints + / - & 1.936 & $1.104-3.393$ & $0.020^{*}$ \\
\hline Neurological complaints + / - & 1.032 & $0.483-2.205$ & 0.935 \\
\hline Chronic fatigue syndrome $+/-$ & 1.627 & $0.706-3.751$ & 0.249 \\
\hline
\end{tabular}

non-hunting groups was approximately equal, and was also insignificant (Tab. 4).

Association of IgG with contact with animals and pets. There was approximately the same probability of incidence of antibodies in the respondents with animal contact at work or with pets in households as in those without the contact; the results were not statistically significant ( $\mathrm{p}>0.05)$ (Tab. 4).

Association of IgG with clinical anamnesis. Analysis revealed a significant association between rheumatologic complaints and anti-Borrelia antibodies (OR=1.936; $\mathrm{CI}=1.104-3.393 ; \mathrm{P}=0.020)$. Respondents with dermatological symptoms had significantly lower seropositivity $(\mathrm{OR}=0.309$; $\mathrm{CI}=0.104-0.912 ; \mathrm{P}=0.026)$ than those without complaints (Tab. 4).

\section{DISCUSSION}

The results of the ELISA method used in the presented study showed $25.3 \%$ seropositive samples and $8.7 \%$ borderline samples. Bazovská et al. [12] reported in the region of western Slovakia the presence of $12.8 \%$ of positive antibodies in healthy blood donors. The high seroprevalence shows an increasing risk of tick infestation in Slovakia.

According to many reports, the risk of contracting diseases transmitted by ticks is greater for forestry workers, farmers and others working in woody [13], brushy, or overgrown grassy areas in the endemic regions [8]. For persons with frequent staying outdoors, $21 \%$ seropositivity was confirmed in the presented study. Police and Customs forces had the lowest seropositivity - 11\%. Education level and shorter time 
of outside rural exposure could be protective factors for tick bite exposure in the group of police workers. Lower positivity among police forces can be also attributed to the higher education of this group, and possible better prevention and personal protection. The agricultural and land workers had almost 3 times higher seropositivity than policemen, with statistical significance $\mathrm{P}=0.029$. These results are comparable with results obtained in Poland, where the level of IgG-class antibodies found in fieldworkers was twice as high as that in office employees [3].

Studies in the adult population of Europe showed that frequency of specific IgG antibodies for B. burgdorferi varied. A few publications focusing on exposed forestry workers and/ or farmers have been noted: Zwolińsky et al. [14] - 32\% and by Chmielevska-Badora et al. [2] - 45.6\% from the Lublin region in Poland; Cisak et al. $[13,15]-40.7 \%$ and $31-41 \%$, respectively, from eastern Poland; Buczek et al. [3] - 25\% in southern Poland; Rojko et al. [16] - 23.8\% from Slovenia. $25 \%$ seropositivity was detected in Spain among persons with outdoor occupations, which is similar to the presented study [17].

A lower seroprevalence was observed by Zhioua et al. [18] with 15.2\% from France; by Bartůnek et al. [19] - 10\% from the Czech Republic; Werner et al. [20] - 7.6\% from Sweden; and by Di Renzi et al. [11] - 3.4\% from Italy. LB is also recorded in other countries outside Europe, e.g., in Turkey $-3.3 \%$, respectively, $10.9 \%[21,8]$. These results were provided by one or two laboratory methods.

The presented study determined that seropositivity was higher in subjects with a rural life than with an urban life, but not significantly. This suggests a more frequent exposure of the rural population to ticks. On the other hand, however, tick infestation is also frequent among the city population due to stays in local forests or city parks.

There was also a gender correlation: males, who may be at greater risk for tick bites, were significantly more likely than females to have anti- $B$. burgdorferi antibodies $(\mathrm{P}=0.045)$. Generally, it was confirmed that men work more frequently in the outdoor environment than women $[1,3,8,11]$.

A significantly higher chance of seropositivity $(\mathrm{P}=0.004)$ was recorded in subjects at the productive age of over 30 years, which seems to be associated with occupational and recreational activities of people in this age group in the environment inhabited by ticks infested with borreliae. Many other studies confirmed increased age as a risk factor [3, $13,17]$.

In this sero-epidemiological report from eastern Slovakia, exposure to tick bites was frequently observed in the investigated group (87\%). Despite this fact, $51 \%$ of respondents exposed to contact with ticks use a repellent to reduce the risk of tick bites. It was shown that in the endemic areas of Poland, over $21 \%$ of exposed people did not use any prophylactics [3]. Di Renzi et al. [11] also noted a lack of individual protective devices among forestry workers. Usage of protective insecticide sprays is mostly underestimated in forestry and agriculture workers. However, in the presented study it was determined that the lowest seropositivity in subjects using repellents was close to the level of significance $(\mathrm{P}=0.070)$. Moreover, Vázquez et al. [22] demonstrated that the use of tick repellents on the skin or clothing while outdoors was also effective (effectiveness of $20 \%$ ) in preventing LB. The risk of LB infection also increases due to the lack of preventive measures against tick infestation. The positivity of antibodies was almost equal in the groups with positive and negative tick bite anamnesis. Thus, the presented study did not confirm a statistical association between seropositivity and tick bite. In some other studies, such an association was also not observed $[8,12]$. It is possible that seroreactive individuals who did not come into contact with a tick, might have been infected with larval stages of I. ricinus, which is likely to be overlooked [5].

Several different studies confirmed the association between the occurrence of antibodies and outdoor activities, e.g., gardening [23] or contact with animals, especially among the cat owners in the households of German children [1] and dog owners [21]. Such a ativities as gardening and hunting appeared as insignificant risk factors in this study $(\mathrm{P}>0.05)$. Furthermore, seropositivity was higher in persons working and frequently staying in the woods and/or on the agricultural field with close significance $\mathrm{P}=0.077$. This result is probably closely associated with occupational and recreational exposure to tick bite in the endemic areas within the current investigated group. Significantly higher seropositivity and contact with animals or pets was not obtained.

The clinical data indicated that a significant number of respondents with musculoskeletal conditions was statistically higher $(\mathrm{P}=0.020)$ in the group with seroreactivity than in the group with non-reactivity. This finding could be associated with LB. The afore-mentioned association has been equally observed in persons with outdoor occupations in Spain [17]. Statistical analysis of the examined group which reported dermatological symptoms showed a lower seropositivity $(\mathrm{P}=0.026)$. This suggests that early dermatologic symptoms of LB in our group - erythema migrans, could probably have been treated in the past by antibiotics. The humoral immune response is late, and an early administration of the antibiotics can postpone or inhibit that response [9], and this fact could explain the absence of antibodies. The other risk factors (neurological problems, chronic fatigue syndrome) were not confirmed as significant.

\section{CONCLUSIONS}

The results of seroprevalence obtained in the presented study confirm the possibility of infection with B. burgdorferi among farmers, forestry workers and other persons exposed to contact with ticks in eastern Slovakia. The result obtained confirm the highest seropositivity in agriculture and forestry workers, middle positivity among other sector workers, and the lowest positivity in policemen and employees of the Customs and Border Inspection. Therefore, it is necessary to increase awareness of the risk population groups with an agenda using prophylactic measures against the risk of tick bite.

\section{Acknowledgements}

This study was supported by Project VVGS - 3/GSD/2012 and Grant VEGA No. 1/0198/13.

\section{REFERENCES}

1. Dehnert M, Fingerle V, Klier C, Talaska T, Schlaud M, Krause G, Wilking H, Poggensee G. Seropositivity of Lyme borreliosis and associated risk factors: a population-based study in children and adolescents in Germany (KiGGS). PLoS One. 2012; 7(8): e41321. 
2. Chmielewska-Badora J, Moniuszko A, Żukiewicz-Sobczak W, Zwoliński J, Piatek J, Pancewicz S. Serological survey in persons occupationally exposed to tick-borne pathogens in cases of co-infections with Borrelia burgdorferi, Anaplasma phagocytophilum, Bartonella spp. and Babesia microti. Ann Agric Environ Med. 2012; 19(2): 271-274.

3. Buczek A, Rudek A, Bartosik K, Szymanska J, Wojcik-Fatla A. Seroepidemiological study of Lyme borreliosis among forestry workers in southern Poland. Ann Agric Environ Med. 2009; 16(2): 257-261.

4. Rizzoli A, Hauffe H, Carpi G, Vourc H G, Neteler M, Rosa R. Lyme borreliosis in Europe. Euro Surveill. 2011; 16(27): 1-8.

5. Štefančíková A, Pet'ko B, Rozická I, Salyova N, Ohlasová D. Epidemiological survey of human borreliosis diagnosed in Eastern Slovakia. Ann Agric Environ Med. 2001; 8(2): 171-175.

6. EPIS. http://www.epis.sk/InformacnaCast/Publikacie/VyrocneSpravy. aspx (access: 2013.09.2013)

7. Biesiada G, Czepiel J, Leśniak MR, Garlicki A, Mach T. Lyme disease: review. Arch Med Sci. 2012; 8(6): 978-982.

8. Kaya AD, Parlak AH, Ozturk CE, Behcet M. Seroprevalence of Borrelia burgdorferi infection among forestry workers and farmers in Duzce, north-western Turkey. New Microbiol. 2008; 31(2): 203-209.

9. Gajović O, Todorović Z, Nesić L, Lazić Z. Lyme borreliosis - diagnostic difficulties in interpreting serological results. Med Pregl. 2010; 63(1112): 839-843 (in Serbian).

10. Bazovská S, Macháčová E, Špaleková M, Kontrošová S. Reported incidence of Lyme disease in Slovakia and antibodies to B. burgdorferi antigens detected in healthy population. Bratisl Lek Listy. 2005; 106(89): 270-273.

11. Di Renzi S, Martini A, Binazzi A, Marinaccio A, Vonesch N, D’Amico W, Moro T, Fiorentini C, Ciufolini MG, Visca P, Tomao P. Risk of acquiring tick-borne infections in forestry workers from Lazio, Italy. Eur J Clin Microbiol Infect Dis. 2010; 29(12): 1579-1581.

12. Bazovská S, Guryčová D, Výrosteková V, Jareková J, Bakoss P, Macháčová E, Špaleková M. Antibodies against the causative agents of some natural focal infections in blood donor sera from Western Slovakia. Epidemiol Mikrobiol Imunol. 2010; 59(4): 168-171 (in Slovak).

13. Cisak E, Chmielewska-Badora J, Zwoliński J, Wójcik-Fatla A, Polak J, Dutkiewicz J. Risk of tick-borne bacterial diseases among workers of
Roztocze National Park (south-eastern Poland). Ann Agric Environ Med. 2005; 12(1): 127-132.

14. Zwoliński J, Chmielewska-Badora J, Cisak E, Buczek A, Dutkiewicz J. Prevalence of antibodies to Anaplasma phagocytophilum and Borrelia burgdorferi in forestry workers from the Lublin region. Wiad Parazytol. 2004; 50(2): 221-227 (in Polish).

15. Cisak E, Zając V, Wójcik-Fatla A, Dutkiewicz J. Risk of tick-borne diseases invarious categories of employment among forestry workers in eastern Poland. Ann Agric Environ Med. 2012; 19(3): 469-474.

16. Rojko T, Ruzić-Sabljić E, Strle F, Lotric-Furlan S. Prevalence and incidence of Lyme borreliosis among Slovene forestry workers during the period of tick activity. Wien Klin Wochenschr. 2005; 117(5-6): 219-225.

17. Arteaga F, Golightly MG, Garcia Perez A, Barral M, Anda P, GarciaMonco JC. Disparity between serological reactivity to Borrelia burgdorferi and evidence of past disease in a high-risk group. Clin Infect Dis. 1998; 27(5): 1210-1213.

18. Zhioua E, Rodhain F, Binet P, Perez-Eid C. Prevalence of antibodies to Borrelia burgdorferi in forestry workers of Ile de France, France. Eur J Epidemiol. 1997; 13(8): 959-962.

19. Bartůnek P, Gorican K, Veiser T, Mrázek V, Varejka P, Hulínská D. The information value of detection of borrelia antibodies in the healthy blood donors and in the population at risk. Cas Lek Cesk. 2007; 146(7): 603-607 (in Czech).

20. Werner M, Nordin P, Arnholm B, Elgefors B, Krantz I. Borrelia burgdorferi antibodies in outdoor and indoor workers in south-west Sweden. Scand J Infect Dis. 2001; 33(2): 128-131.

21. Aslan Başbulut E, Gözalan A, Sönmez C, Cöplü N, Körhasan B, Esen B, Akın L, Ertek M. Seroprevalence of Borrelia burgdorferi and tick-borne encephalitis virus in a rural area of Samsun, Turkey. Mikrobiyol Bul. 2012; 46(2): 247-256 (in Turkish).

22. Vázquez M, Muehlenbein C, Cartter M, Hayes EB, Ertel S, Shapiro ED. Effectiveness of personal protective measures to prevent Lyme disease. Emerg Infect Dis. 2008; 14(2): 210-216.

23. Cinco M, Barbone F, Grazia Ciufolini M, Mascioli M, Anguero Rosenfeld M, Stefanel P, Luzzati R. Seroprevalence of tick-borne infections in forestry rangers from northeastern Italy. Clin MicrobiolInfect. 2004; 10(12): 1056-1061. 